\title{
IMMUNE RESPONSES TO RNA-VIRUS INFECTIONS OF THE CNS
}

\begin{abstract}
Diane E. Griffin
A successful outcome for the host of virus infection of the central nervous system (CNS) requires

the elimination of the virus without damage to essential non-renewable cells, such as neurons. As

a result, inflammatory responses must be tightly controlled, and many unique mechanisms seem

to contribute to this control. In addition to being important causes of human disease, RNA viruses

that infect the CNS provide useful models in which to study immune responses in the CNS.

Recent work has shown the importance of innate immune responses in the CNS in controlling

virus infection. And advances have been made in assessing the relative roles of cytotoxic $T$ cells,

antibodies and cytokines in the clearance of viruses from neurons, glial cells and meningeal cells.
\end{abstract}

Virus infections of the central nervous system (CNS) are relatively uncommon, but potentially devastating. The longevity of many cells in the CNS and the relative inaccessibility of this tissue to components of the immune system make the brain and spinal cord particularly susceptible to persistent virus infection. Because of the potential for neurological damage by inflammatory mediators and cytotoxic cells, the brain has intrinsic mechanisms for controlling immune responses that are different from other organs. Nevertheless, many virus infections are cleared from the CNS through virus-specific immune mechanisms without marked neurological damage. Clearance of virus from nonneural tissues often involves cytolytic elimination of the infected cells. However, immune responses to virus infection of the CNS can also clear the virus from the tissue or sustain prolonged inhibition of virus replication without damage to the structure or function of the nervous system. Non-cytolytic clearance mechanisms are advantageous to the host when the infected cells cannot be replaced, but they might provide less complete elimination of the virus than cytolytic processes. Mechanisms for non-cytolytic clearance are beginning to be elucidated and new roles have been identified for lymphocytes, local antibody production and cytokines. The degree to which clearance is successful differs with the type of virus that causes the infection and with the target cells that the virus infects.

\section{Types of virus that infect the CNS}

Several RNA and DNA viruses from different virus families can infect the nervous system and cause human disease (TABLE 1). DNA viruses that infect the CNS have nuclear phases in their replication cycles and often have an inherent capacity to remain latent in the nucleus (and undetectable to the immune system), either by integrating a copy of the virus genome into host DNA or by maintaining an episomal form of the virus genome in the cell nucleus. These viruses are common causes of disease in immunocompromised hosts because of their ability to reactivate when host immune responses fail. Most RNA viruses replicate only in the cytoplasm and do not establish true latency and, therefore, are susceptible to different mechanisms of immune control than are DNA viruses. This review focuses on the immune response to RNA viruses in the CNS.

The viruses and their target cells. The most common virus infections of the CNS cause meningitis by targeting the cells of the leptomeninges that cover the surface of the brain. These viruses do not usually cause serious disease or persistent infection because they infect renewable cells in a part of the nervous system that is accessible to the immune system. Less common, but more likely to cause fatal disease, are viruses that infect neurons. Neurons are long-lived, terminally differentiated cells that are important target cells for viruses causing 


\begin{tabular}{|c|c|c|}
\hline \multicolumn{3}{|c|}{ Table 1 | Examples of important virus infections of the CNS } \\
\hline Virus & Primary target cell & Geographical distribution \\
\hline \multicolumn{3}{|l|}{ DNA } \\
\hline Herpes simplex virus & Neurons & Worldwide \\
\hline Human herpesvirus 6 & Oligodendrocytes & Worldwide \\
\hline Cytomegalovirus & Neurons & Worldwide \\
\hline Adenovirus & Neurons, ependyma & Worldwide \\
\hline JC virus & Oligodendrocytes & Worldwide \\
\hline \multicolumn{3}{|l|}{ RNA } \\
\hline Poliovirus & Motor neurons & India, Africa \\
\hline Coxsackie virus & Meninges & Worldwide \\
\hline $\mathrm{ECHO}$ virus & Meninges & Worldwide \\
\hline Enterovirus 71 & Neurons & Asia, \\
\hline Japanese encephalitis virus & Neurons & Asia, Australia \\
\hline West Nile virus & Neurons & Europe, Americas, Africa \\
\hline St Louis encephalitis & Neurons & USA \\
\hline Eastern equine encephalitis virus & Neurons & Americas \\
\hline Venezuelan equine encephalitis virus & Neurons & Americas \\
\hline LaCrosse virus & Neurons & USA \\
\hline Lymphocytic choriomeningitis virus & Meninges & Worldwide \\
\hline Rabies virus & Neurons & Europe, Asia, Africa, Americas \\
\hline Mumps virus & Meninges, ependyma & Worldwide \\
\hline \multicolumn{3}{|l|}{ Retrovirus } \\
\hline HIV & Microglia & Worldwide \\
\hline Human T lymphotropic virus I & Astrocytes & Japan, Caribbean \\
\hline
\end{tabular}

BLOOD-BRAIN BARRIER

This is formed by endothelial tight junctions that limit entry of leukocytes, immunoglobulins, cytokines and complemen proteins into the central nervous system.

TYPE 1 INTERFERON

(Type 1 IFN). IFN- $\alpha$ and IFN- $\beta$ are induced by virus replication and are important early inducers of anti-virus immune responses. They limit virus replication before the antigenspecific immune response. encephalomyelitis (BOX 1). Not all types of neuron are equally susceptible or likely to become infected; this depends on the virus tropism, route of entry of the virus into the CNS and the mechanism of spread. Many neuronotropic viruses spread within the nervous system by axonal transport and move from neuron to neuron through connecting synapses ${ }^{1}$. If infection is induced experimentally by intracerebral inoculation, there might also be rapid spread through the cerebrospinal fluid ${ }^{2}$. Other viruses target the supporting glial cells of the CNS — oligodendrocytes, astrocytes and microglia — alone or in addition to neurons. Oligodendrocytes form and maintain the myelin that surrounds the axons of neurons, and infection of these cells might lead to acute or chronic demyelinating disease. Astrocytes are the 'supporting' cells for neurons. Among other functions, they produce neurotrophic factors, remove toxic materials and maintain the BLOOD-BRAIN BARRIER. Infection of these cells might also indirectly damage neurons. Microglia are the resident macrophages of the CNS, can express MHC class I and class II molecules, have an important role in local immune responses and can produce various factors that are toxic to neurons.

Mouse models of infection. Most of our knowledge about immune responses to virus infection of the CNS comes from studying a few well-characterized mouse models of infection that characterize these types of virus-induced disease (TABLE 2). The most detailed studies of immune responses to neuronal infection have been with rabies virus and mosquito-borne alphaviruses, such as Sindbis virus, Venezuelan equine encephalitis virus and Semliki Forest virus, that can cause acute encephalomyelitis in mice. The most extensive studies of immune responses to viruses that infect glial cells, often in addition to neurons, have involved the natural mouse pathogens Theiler's mouse encephalomyelitis virus (TMEV), which is a picornavirus, and mouse hepatitis virus (MHV), which is a coronavirus. Another natural mouse pathogen, lymphocytic choriomeningitis virus (LCMV), which is an arenavirus that can infect ependymal cells, choroid plexus cells or neurons, has also been studied extensively. LCMV, as well as Borna disease virus, can cause immune-mediated disease and persistent infection of the CNS. For all of these RNA viruses, the outcome of infection depends on the age and genetic background of the mouse, and on the strain of virus that is studied. For this review, the focus is on immune responses of adult animals to the most commonly studied strains of each virus. These infections have many common, as well as distinctive, features. Immune responses to each infection progress through several phases that start with intrinsic responses in the CNS as the presence of the pathogen is recognized, followed by entry of lymphocytes and monocytes from the periphery as part of the adaptive inflammatory response, and then complete or partial silencing of immune-mediated inflammation as the virus is cleared or its replication is controlled.

Innate immune responses to CNS virus infection

The normal, uninfected CNS lacks immunological activity. Endothelial cells have intact tight junctions and express low levels of adhesion molecules that promote interaction with circulating leukocytes. Microglia, which express the CD200 receptor (CD200R), are kept in a quiescent state through interaction with electrically active, healthy neurons, which express CD200 (REF. 3), and by the local production of neurotrophins ${ }^{4}$. Production of the anti-inflammatory cytokine transforming growth factor- $\beta$ (TGF- $\beta$ ) by astrocytes and meningeal cells suppresses activation of endothelial and other cells by cytokines ${ }^{5,6}$ (FIG. 1a).

When neurons or other CNS cells become infected, changes quickly occur to initiate protective responses (FIG. 1b). Rapid production of TYPE 1 INTERFERON (IFN) is important for host survival and, in most experimental virus infections of the CNS, susceptibility to fatal disease is markedly increased in mice that lack the receptor for IFN- $\alpha / \beta^{7-10}$. IFN- $\beta$, an immediate early IFN, which is produced by neurons as well as glial cells, is the main type 1 IFN that is produced by the CNS and is required for efficient induction of IFN- $\alpha$ in $v i t r 0^{11,12}$. Preferential production of IFN- $\beta$ rather than IFN- $\alpha$ in the CNS might be neuroprotective, as IFN- $\alpha$ has marked CNS toxicity compared with IFN- $\beta^{13,14}$, and IFN- $\beta$ might induce the production of neurotrophic factors by astrocytes ${ }^{15}$ and the local production of the anti-inflammatory cytokine interleukin-10 (IL-10) ${ }^{16}$. Rapid local production of type 1 IFN after infection 


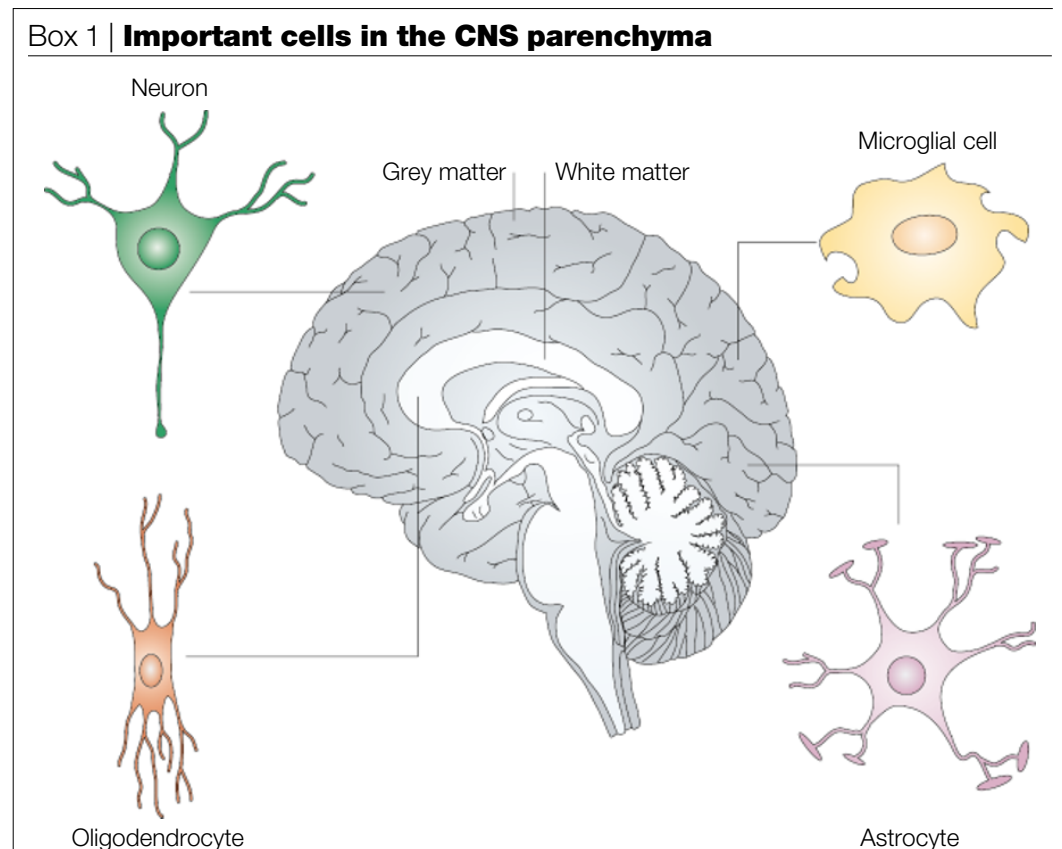

- Neurons are electrically active cells that transmit signals from the periphery and within the central nervous system (CNS). They are located in the grey matter of the brain and spinal cord.

- Astrocytes are glial cells that are located in close proximity to neurons. They are responsible for secreting neuroprotective factors and for the local metabolism of toxins and neurotransmitters.

- Oligodendrocytes are myelin-producing cells that are found in the white matter wrapping the axons of neurons. Myelin insulates the axons and enhances the efficiency of conduction of electrical signals between neurons.

- Microglia are bone-marrow-derived macrophage-lineage cells that become immunologically active early during CNS injury and the induction of inflammation.

DELAYED-TYPE HYPERSENSITIVITY A cellular immune response to antigen that develops over 24-72 hours with the infiltration of $\mathrm{T}$ cells and monocytes, and is dependent on the production of Thelper 1-type cytokines. slows virus spread and constrains virus replication before the induction of virus-specific adaptive immune responses. Virus inhibition of type 1 IFN production or activity - for example, by the leader protein of TMEV - increases the probability that the virus will not be cleared $^{17}$.

Damaged or stressed neurons signal to astrocytes and microglia in the vicinity of the neuronal cell body, even when the neuronal damage occurs to the axon at a distance ${ }^{18}$. The factors that are produced by neurons in response to injury - which includes injury caused by virus infection - are not completely catalogued, but they probably include the cytokines IFN- $\gamma$ and IL-6, and the chemokines fractalkine (CX3CL1) and secondary lymphoid tissue chemokine (SLC, CCL21), in addition to IFN- $\beta^{19-21}$. CX3CL1 is a membrane-bound chemokine that is constitutively expressed by subsets of neurons and is rapidly cleaved from the cell surface after neurotoxic damage ${ }^{22}$. Macrophages and glial cells express the CX3CL1 receptor (CX3CR1) and so become activated in early phases of the response to neuronal infection ${ }^{23,24}$, in which they have an important role. Activated microglia and astrocytes can rapidly produce an array of cytokines and chemokines. These vary with the specific virus infection, but frequently include IL-1, IL-6, IL-12, tumour-necrosis factor (TNF), macrophage inflammatory protein-1 $\beta$ (MIP1 $\beta$, CCL4), monocyte chemoattractant protein 1 (MCP1, CCL2), MCP3 (CCL7), regulated on activation normal $\mathrm{T}$-cell expressed and secreted (RANTES, CCL5) and IFN-inducible $10 \mathrm{kDa}$ protein (IP10, CXCL10) ${ }^{25-30}$. Production of these factors results in the upregulation of expression of MHC molecules on the cell surface of microglia and in increased expression of adhesion molecules by capillary endothelial cells. Chemokines are transcytosed to the endothelial luminal surface and presented to circulating leukocytes on the tips of microvillous processes ${ }^{31}$.

\section{Induction of the adaptive immune response}

The normal brain is relatively deficient in expression of MHC molecules, and the structure of the blood-brain barrier inhibits the entry of circulating proteins and cells from the blood to the brain parenchyma. It is generally agreed that, although there are cells that can present antigen to primed T cells in the CNS, the activation of naive T cells and B cells occurs in secondary lymphoid tissues outside the $\mathrm{CNS}^{32-34}$. The parenchyma of the normal CNS does not contain dendritic cells, although they are present in the meninges and cerebrospinal fluid $(\mathrm{CSF})^{35}$. Some of the CSF and CNS interstitial fluid drains to the deep cervical lymph nodes through the nasal submucosa ${ }^{32,36}$. Experimental inoculation of virus directly into the CSF elicits a potent immune response, whereas inoculation directly into the brain parenchyma elicits little or no response ${ }^{37}$. Responses that are initiated by inoculation of antigen into the CSF tend to be characterized by marked antibody responses, priming of cytotoxic $\mathrm{CD} 8^{+} \mathrm{T}$ cells and no DELAYED-TYPE HYPERSENSITIVITY ${ }^{32}$. However, essentially all neurotropic viruses naturally initiate infection in the periphery either through the gastrointestinal tract, the respiratory tract or the bite of an infected mosquito or animal. Therefore, induction of the virus-specific immune response occurs through virus infection, or uptake by dendritic cells in peripheral tissue and antigen presentation in lymph nodes that drain those initial sites of replication, rather than in the CNS.

The entry of circulating leukocytes into the CNS is generally restricted by the tight junctions and by the relative nonreactivity of cerebral capillary endothelial cells, which have limited endocytosis and expression of adhesion molecules ${ }^{38,39}$. However, several studies have shown that activated $\mathrm{T}$ cells routinely cross the blood-brain barrier as part of the normal immunological surveillance of all tissues ${ }^{39-41}$ (FIG. 1a). Transendothelial migration of activated $\mathrm{CD} 4^{+} \mathrm{T}$ cells occurs, in part, through the interaction of P-selectin glycoprotein ligand, which is expressed by activated T cells, with P-selectin, which is expressed at low levels by normal cerebrovascular endothelial cells ${ }^{38,42}$. However, one side effect of the induction of a systemic immune response, even in the absence of infection in the CNS, is the upregulation of expression of adhesion molecules by CNS endothelial cells and increased surveillance of the CNS by activated $\mathrm{T}_{\text {cells }}{ }^{43,44}$. Activated T cells that enter the CNS are not retained in the CNS in the absence of antigen, and 


\begin{tabular}{|c|c|c|c|}
\hline Virus & Cells infected & Mechanisms of virus clearance & References \\
\hline Theiler's mouse encephalomyelitis virus & Neurons, microglia, oligodendrocytes & CD8 ${ }^{+} \mathrm{T}$ cells, antibody & 78,101 \\
\hline Sindbis virus & Neurons & Antibody, IFN- $\gamma$ & $46,80,94$ \\
\hline Mouse hepatitis virus & $\begin{array}{l}\text { Neurons } \\
\text { Microglia, astrocytes } \\
\text { Oligodendrocytes }\end{array}$ & $\begin{array}{l}\text { CD8 }{ }^{+} T \text { cells, antibody } \\
\text { CD4 }{ }^{+} T \text { cells, CD8 }{ }^{+} T \text { cells, B cells } \\
\text { IFN- } \gamma\end{array}$ & $\begin{array}{r}61,79 \\
103-105,107,111 \\
106\end{array}$ \\
\hline Lymphocytic choriomeningitis virus & Choroid plexus, meninges, neurons & CD8 ${ }^{+} \mathrm{T}$ cells & 96 \\
\hline Rabies virus & Neurons & Antibody, CD4 ${ }^{+} \mathrm{T}$ cells, CD8 ${ }^{+} \mathrm{T}$ cells & 81,87 \\
\hline Vesicular stomatitis viurs & Neurons & IFN- $\gamma$, nitric oxide & 95 \\
\hline
\end{tabular}

CNS, central nervous system; IFN- $\gamma$, interferon- $\gamma$.

T HELPER $1 / 2$ CELLS

$\left(\mathrm{T}_{\mathrm{H}} 1 / 2\right)$. At least two distinct subsets of activated $\mathrm{CD} 4^{+} \mathrm{T}$ cells have been described. $T_{H} 1$ cells produce interferon- $\gamma$, lymphotoxin and tumournecrosis factor, and support cellmediated immunity. $\mathrm{T}_{\mathrm{H}} 2$ cells produce interleukin-4 (IL-4), IL-5 and IL-13, support humoral immunity and downregulate $\mathrm{T}_{\mathrm{H}} 1$-cell responses.

GANGLIOSIDES Sialic acid-containing glycosphingolipids that are constituents of plasma membranes. They are enriched in the brain and can be shed from the cell surface as regulatory molecules. either leave or die in situ (FIG. 1a). However, activated $\mathrm{T}$ cells are retained in the CNS when the relevant antigen is present and associated with appropriate MHC molecules ${ }^{39}$. During inflammation, local production of chemokines and induction of expression of adhesion molecules by endothelial cells further enhance the entry of activated cells into the $\mathrm{CNS}^{45}$. Expression of intercellular adhesion molecule 1 (ICAM1, CD54) and vascularcell adhesion molecule 1 (VCAM1) is upregulated by cerebral capillary endothelial cells during virus infection, and antibody specific for the integrin leukocyte function-associated antigen 1 (LFA1), which is the ligand for ICAM1, blocks lymphocyte entry into the brain during the acute inflammatory response to Sindbis virus ${ }^{39}$.

MHC class I molecules are not expressed by cells in the normal CNS, but are abundantly expressed by endothelial, meningeal and microglial cells during the early phases of the immune response to most CNS virus infections ${ }^{46}$, and are occasionally expressed by astrocytes and oligodendrocytes ${ }^{47}$. However, neurons rarely express MHC class I molecules. Neurons respond to IFN- $\beta$ with induction of antiviral proteins, such as $2^{\prime}-5^{\prime}$ oligoadenylate synthetase, but not with expression of MHC class I molecules ${ }^{48}$. Suppression of expression of MHC class I molecules by neurons seems to be both transcriptional and post transcriptional. There is little translocation from the cytoplasm to the nucleus of nuclear factor- $\mathrm{\kappa B}(\mathrm{NF}-\mathrm{\kappa B})$ - a key transcription factor for MHC class I expression - in neurons in response to pro-inflammatory mediators for example, TNF and IL-1 or virus infection, despite the presence of these receptors. By contrast, astrocytes readily respond in this manner. Lack of NF- $\kappa B$ translocation in neurons seems to be due to a failure to induce degradation of the inhibitor of NF- $\kappa \mathrm{B}(\mathrm{I} \kappa \mathrm{B} \alpha)$ in response to cytokines ${ }^{48,49}$. However, neurons that are damaged or electrically silenced by treatment with a neurotoxin can be induced to express MHC class I molecules by treatment with IFN- $\gamma^{50}$. In vivo, the levels of mRNAs that encode MHC class I heavy chain, $\beta_{2}$-microglobulin $\left(\beta_{2} \mathrm{~m}\right)$, transporter associated with antigen processing 1 (TAP1) and TAP2 are increased in neurons during infection ${ }^{46}$. However, there is controversy over whether mature MHC class I molecules are expressed on the neuronal cell surface ${ }^{46,51}$. The $\beta_{2} \mathrm{~m}$ molecules that are sometimes detected on the neuronal cell surface might be associated with expression of non-classical rather than classical MHC class I molecules. Differences in sensitivity of detection might also account for some of the controversy that surrounds this issue - when expression of MHC class I molecules by neurons is detected, it is at markedly lower levels than expression by glial cells in the same region ${ }^{51}$.

MHC class II molecules are not constitutively expressed by cells in the brain parenchyma, but are induced quickly after initiation of infection and also by trafficking of activated $\mathrm{T}$ cells through the $\mathrm{CNS}^{52}$. The cells that express MHC class II molecules most abundantly are microglia and perivascular macrophages ${ }^{34}$. Astrocytes can be induced to express MHC class II molecules in vitro, but this is rarely observed in vivo ${ }^{34}$.

Infiltration of mononuclear inflammatory cells into the CNS begins three to four days after infection. Cells first accumulate in perivascular areas and then infiltrate the parenchyma in the regions of virus infection. Essentially all components of the cellular immune response are detected in the infiltrate: natural killer (NK) cells, antigen-specific $\mathrm{CD} 4^{+}$and $\mathrm{CD}^{+} \mathrm{T}$ cells, $B$ cells and monocyte/macrophages ${ }^{53-57}$. NK cells are detected first, followed by $\mathrm{CD} 8^{+}$and $\mathrm{CD} 4^{+} \mathrm{T}$ cells, then $B$ cells and monocytes/macrophages ${ }^{58}$. In addition, dendritic cells are detected in the CNS during inflammation and either enter the CNS from the circulation or develop from a subpopulation of activated microglia ${ }^{33,59}$. The number of inflammatory cells peaks within one to two weeks after infection and then these cells are gradually eliminated, unless the virus persists ${ }^{60}$. Cytokines that are produced by these infiltrating cells include IFN- $\gamma$, IL-4 and IL-10, but rarely IL-2 (REFS 27-29,54,61,62). B cells in the CNS usually produce antibody, mainly of the immunoglobulin A and IgG subclasses ${ }^{63}$, although IgA is not produced in response to all infections.

\section{Regulation of immune responses in the CNS}

Several observations indicate that there is marked regulation of immune responses in the CNS. Active regulation includes functional control of the immune activation of intrinsic cells of the CNS and of cells entering the CNS. In addition, there is induced death of T cells that infiltrate the brain. Several regulatory mechanisms are involved and these tend to inhibit T-cell proliferation and favour the production of T HELPER $2\left(\mathrm{~T}_{\mathrm{H}} 2\right)$-type cytokines, although these cytokines might not have an important role in clearance per se. CNS GANGLIOSIDES 


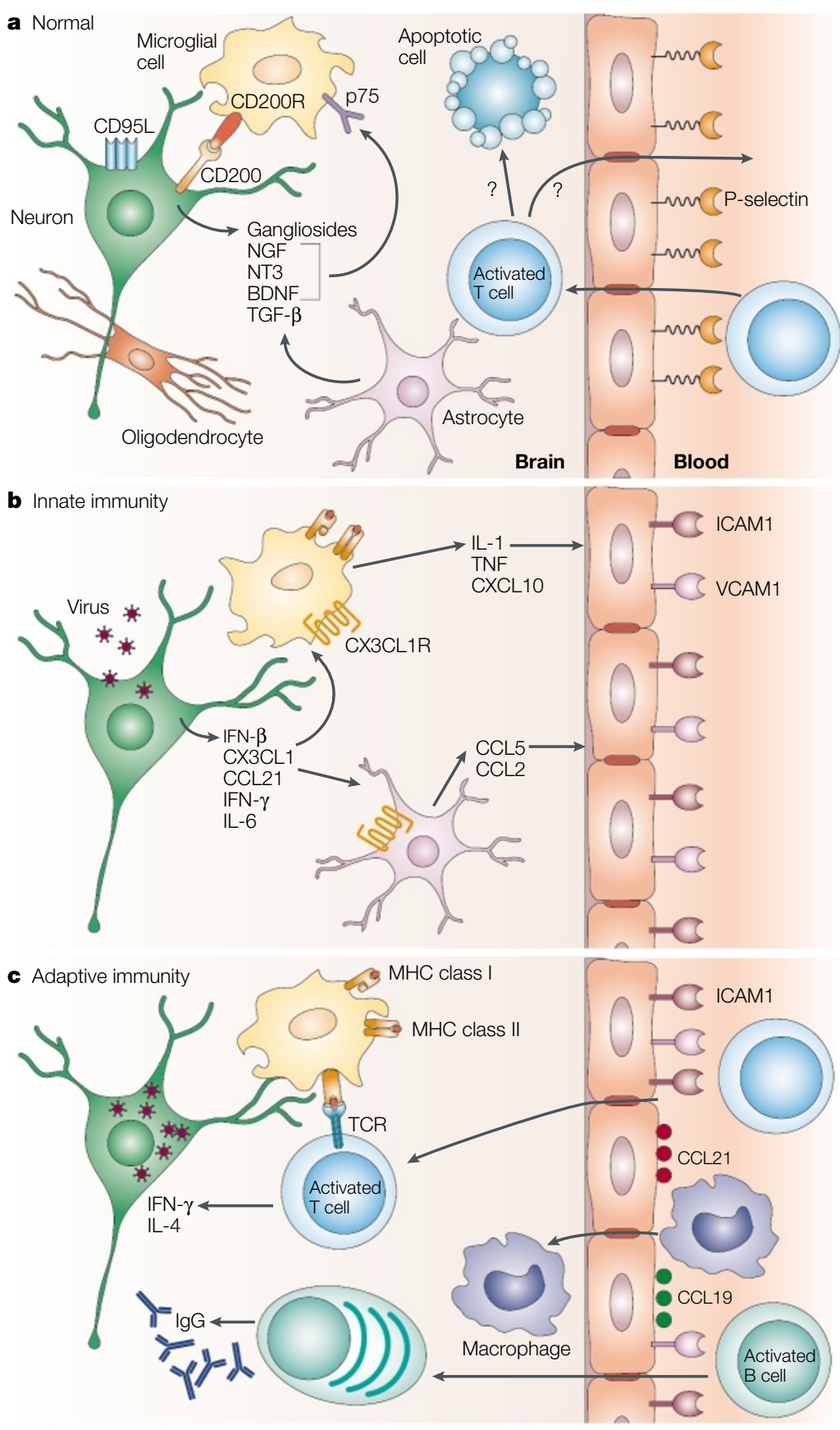

Figure 1 | Changes that occur in the CNS during the immune response to a neuronal virus infection. a In the normal uninfected central nervous system (CNS), endothelial cells express few adhesion molecules. Neurons maintain microglia in a quiescent state through CD200-CD200 receptor (CD200R) interactions and astrocytes contribute by the production of neurotrophins, such as brain-derived neurotrophic factor (BDNF), nerve-growth factor (NGF) and neurotrophin 3 (NT3), that interact with p75, a low-affinity neurotrophin receptor. Gangliosides are abundant and transforming growth factor- $\beta$ (TGF- $\beta$ ) is constitutively produced by neurons and astrocytes. Activated T cells enter the CNS routinely through interaction with low levels of P-selectin expressed by endothelial cells, but leave or die soon thereafter. $\mathbf{b}$ |Virus infection of neurons initiates the early production of interferon- $\beta$ (IFN- $\beta$ ), chemokines and pro-inflammatory cytokines, which results in further activation of microglia and increased expression of adhesion molecules, such as vascularcell adhesion molecule 1 (NCAM1) and intercellular adhesion molecule 1 (ICAM1), by endothelial cells. c | By three to four days after infection, inflammatory cells - such as natural killer (NK) cells, macrophages and lymphocytes - that are activated in secondary lymphoid tissue begin to enter the CNS at regions where virus replication is occurring and chemokines, such as CCL19 and CCL21, are expressed by endothelial cells. T cells produce additional cytokines, such as interleukin-4 (IL-4) and IFN- $\gamma$, and the B cells produce antibody, which initiates clearance of virus from infected cells. TNF, tumour-necrosis factor. inhibit the expression of MHC class I and class II molecules by astrocytes and inhibit IL-2 production and proliferation of $\mathrm{T}$ cells in the brain parenchyma without affecting the production of IL-4 or IL-5. The immunoregulatory activity of brain gangliosides on $\mathrm{T}$ cells is due, in part, to suppression of NF- $\mathrm{BB}$ activity and phosphorylation of retinoblastoma protein ${ }^{64-66}$. $T$ cells from strains of mice that are susceptible to $T_{H} 1$ mediated autoimmune disease of the CNS are less responsive to regulation by brain gangliosides than $\mathrm{T}$ cells from disease-resistant strains ${ }^{67}$.

However, ganglioside production by neurons does not inhibit the expression of MHC class II molecules by microglia ${ }^{4,68}$. Antigen presentation by microglia stimulates $\mathrm{CD} 4^{+} \mathrm{T}$ cells to produce IFN- $\gamma$, but not IL- 2 and does not stimulate T-cell proliferation. By contrast, macrophages that infiltrate the CNS from the periphery, which tend to accumulate near vessels, can support complete T-cell activation and survival ${ }^{69}$. Activity of these macrophages might be controlled by the production of TGF- $\beta$ in the CNS, which suppresses the development of T-cell cytotoxicity and delayed-type hypersensitivity, and which deactivates infiltrating antigen-presenting cells (APCs) $)^{70,71}$.

Activated $\mathrm{T}$ cells that leave the perivascular area often undergo apoptosis after exposure to APCs in the parenchyma ${ }^{72,73}$. In addition, constitutive expression of FAS ligand (CD95L) by cells of the CNS induces apoptosis of FAS (CD95)-expressing activated T cells. Neuronal expression of CD95L might further protect neurons from T-cell cytotoxicity ${ }^{74-76}$.

Mechanisms of immune-mediated virus clearance Clearance strategies. Clearance of virus from cells in the brain parenchyma is a multistep process. Each of the several phases of virus clearance are assessed in different ways. First, there is inhibition of virus spread to new cells, then elimination of cell-free infectious virus. Subsequently, virus-infected cells must be eliminated or intracellular virus replication permanently suppressed. The most frequently measured parameter of virus clearance is the amount of infectious virus that is present in CNS tissue. However, as antibody specific for the virus is produced, the ability to detect infectious virus by standard assays, which depend on the detection of viral cytopathic effects in susceptible indicator cells, is compromised by the presence of neutralizing antibody in the tissue homogenates. During this phase of clearance, virus can often be detected by cocultivation of cells from the infected tissue with susceptible tissue culture cells. As replication in cells is suppressed or infected cells are eliminated, quantitative measurement of virus nucleic acid provides the best indicator of whether the virus has truly been eliminated from the relevant cells and tissue.

There is no doubt that the most reliable way to completely eliminate a virus from tissue is to eliminate all cells in which the virus is replicating, either by virus-induced cytolysis or by immune-mediated cytolysis. However, mature CNS neurons and many glial cells are relatively resistant to both processes. The fact that neurons are non-renewable cells might underly 
their resistance to apoptosis. If infected cells are allowed to survive, the clearance of virus must include mechanisms for inhibiting intracellular synthesis of virus nucleic acid and protein, and for removing virus genomes from cells. If the clearance process is not complete, then mechanisms for preventing resumption of virus replication must be in place to avoid progressive or relapsing disease ${ }^{58,60,77}$.

The immunological processes that are required for clearance are cell-type specific. Therefore, control might be achieved in one target-cell population (for example, neurons), but not another (for example, microglia or oligodendrocytes). In general, antibody responses have an important role in the clearance of viruses from neurons, whereas T-cell-mediated responses are more important for clearance from glial cells, for reasons that are not yet understood. However, as with any important biological process, mechanisms for the control of virus replication are redundant and overlapping. Experimental approaches to define these clearance mechanisms are dependent on the transient depletion of specific immune-cell populations and on the use of mice that have selective deficiencies in various components of the immune system. Because of the interdependent relationships of components of the immune system in the development of an immune response, deficiencies of one type of cell or molecule might affect several facets of the immune response, making it difficult to identify specific effectors that are crucial for in vivo clearance.

Clearance from neurons. For most RNA viruses, clearance of virus from neurons occurs through a noncytolytic, immunologically specific process. Anti-viral antibodies are important for the clearance of rabies virus, Sindbis virus, MHV and TMEV from neurons ${ }^{78-81}$. $\mathrm{B}$ cells, including virus-specific antibody-secreting cells, infiltrate the brain as a part of the inflammatory response and are retained in the $\mathrm{CNS}^{57,82,83}$ (FIG. 1c). Many of the specific antibodies that are associated with protection or clearance are directed against virus surface proteins and inhibit intracellular virus replication in vitro ${ }^{80,84}$. The mechanism by which antibody specific for a virus surface glycoprotein inhibits virus replication is not completely clear, but has been studied in greatest detail for Sindbis virus.

The anti-viral effect of antibody specific for the Sindbis virus E2 glycoprotein does not require complement or phagocytic cells, but does require that the antibody be bivalent ${ }^{80,84}$. This implies that crosslinking of virus proteins on the surface of the infected cell is necessary for the control of intracellular virus replication. Treatment of persistently infected cells with antibody leads to the restoration of sodium-pump function and synthesis of host proteins, both of which are inhibited by Sindbis-virus replication ${ }^{85}$. Type 1 IFN synergizes with antibody to further inhibit virus replication, and it is probable that this interaction is important for the clearance of virus in vivo ${ }^{86}$. Antibody is also necessary for the clearance of rabies virus ${ }^{87}$ and MHV from neurons ${ }^{79}$. The 'clearance' of Sindbis virus and other viruses that infect neurons is incomplete, as virus RNA can be detected throughout the life of the animal ${ }^{82,88}$. Longterm secretion of antibody in the brains of mice that have recovered from infection indicates that there is a continued requirement for immune-mediated control of virus replication ${ }^{57,82}$.

Although studies of immunodeficient mice show that $\mathrm{T}$ cells are not necessary for the clearance of Sindbis virus from neurons, the level of intracellular virus RNA is reduced more rapidly when $\mathrm{CD} 8^{+} \mathrm{T}$ cells are present ${ }^{46}$. $\mathrm{CD}^{+} \mathrm{T}$ cells are also important for rapid control of rabies virus and herpes simplex virus replication in neurons $^{87,89}$. In general, $\mathrm{CD} 8^{+} \mathrm{T}$ cells can exert anti-viral effector functions either through a non-lytic cytokinemediated pathway or by a cytotoxic pathway, which involves either the cytotoxic effector molecules perforin and granzymes or CD95-CD95L. It is not known whether $\mathrm{CD} 8^{+} \mathrm{T}$ cells in the CNS are activated by the virus-peptide-MHC class I complexes expressed by virus-infected neurons or by surrounding glial cells that have taken up antigen released by infected cells a process known as cross-priming. Neurons are severely restricted in their expression of MHC class I molecules, but MHC class I expression has been observed in damaged neurons that were exposed to IFN- $\gamma$ and occasionally on virus-infected neurons ${ }^{51,90}$. CD8 ${ }^{+} \mathrm{T}$-cell-mediated killing of neurons through a CD95-CD95L-dependent pathway has also been documented ${ }^{74,91}$. Although neuronal death mediated by $\mathrm{CD}^{+} \mathrm{T}$ cells has been reported in some virus infections of the $\mathrm{CNS}^{92}$, the main contributions of $\mathrm{CD} 8^{+} \mathrm{T}$ cells to the clearance of virus from neurons are not mediated through cytolysis of infected cells, and do not require perforin or CD95 (REF.93).

Recent studies of antibody-deficient mice have shown that both $\mathrm{CD}^{+}$and $\mathrm{CD}^{+} \mathrm{T}$ cells infiltrating the brain contribute to the clearance of Sindbis virus through the production of IFN- $\gamma^{94}$. An important role for $\mathrm{CD} 4^{+}$and $\mathrm{CD} 8^{+} \mathrm{T}$ cells in virus clearance that is associated with the production of IFN- $\gamma$ has also been shown for a neuronotropic strain of $\mathrm{MHV}^{61}$. IFN- $\gamma$ also has a role in the clearance of vesicular stomatitis virus, a virus that is related to rabies virus, from neurons, perhaps through the production of nitric oxide ${ }^{95}$. $\mathrm{CD} 8^{+} \mathrm{T}$ cells alone can clear LCMV from persistently infected neurons after a prolonged period of time ${ }^{96}$ and these cells might produce anti-viral factors in addition to IFN- $\gamma$. For example, the cytotoxic effector molecule granzyme A seems to have an additional role in restricting the replication of herpes simplex virus in neurons ${ }^{97}$. However, in contrast to its essential role in non-cytolytic clearance of hepatitis B virus from hepatocytes, there is no evidence of a role for TNF in clearing virus from neurons ${ }^{94,98}$.

Interestingly, neurons in different regions of the CNS differ in their ability to respond to the anti-viral effects of IFN- $\gamma$. Motor neurons in the spinal cord show complete resolution of infection in the absence of antibody, whereas cortical neurons require antibody for the clearance of Sindbis virus ${ }^{94}$. Whether this is due to differences in the ability to bind IFN- $\gamma$ or to differences in the ability to respond to IFN- $\gamma$ is not known. The IFN- $\gamma$ receptor is widely expressed by neurons and constitutive expression by neurons is markedly higher than it is by glial cells ${ }^{99}$. 
a

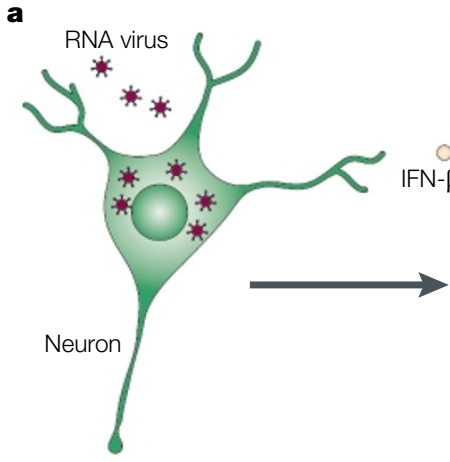

Infection

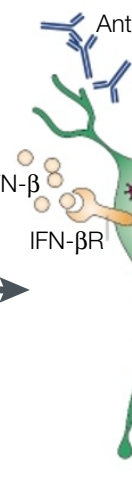

IFN- $\beta R$ (n)
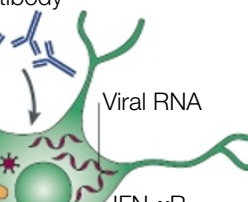

* IFN- $\gamma \mathrm{R}$

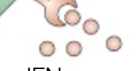

$\mathrm{IFN}-\gamma$

(n)

b

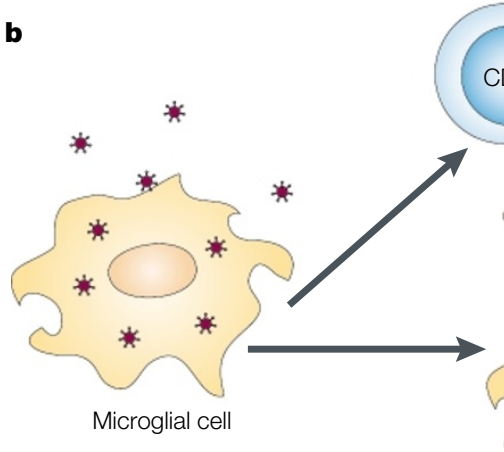

Microglial cell
Control and clearance
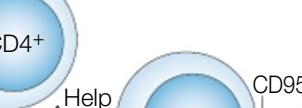

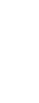
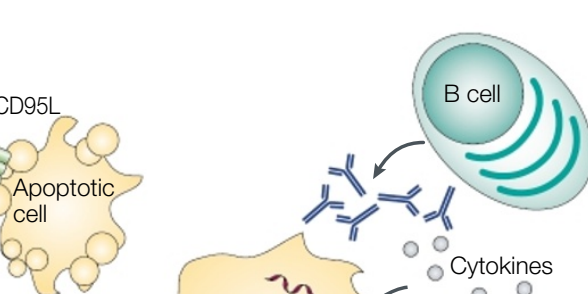

Long-term control

Cytokines

$\begin{array}{lll}0 & \\ 0 & 0\end{array}$

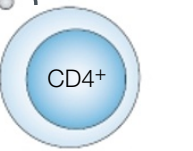

$4^{+}$ Cytokines

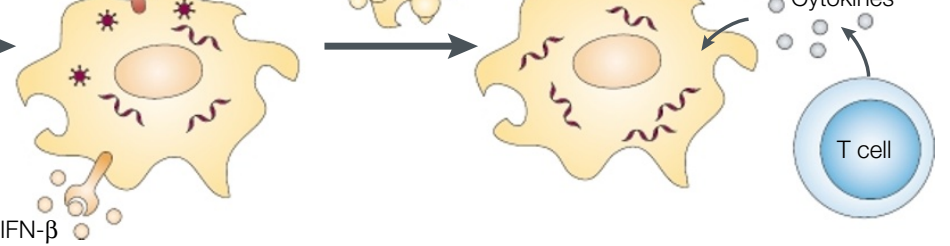

Figure 2 | Mechanisms of virus clearance from neurons and microglia. $\mathbf{a} \mid$ In neurons that survive infection with RNA viruses, infection is controlled initially by interferon- $\beta$ (IFN- $\beta$ ) and subsequently by virus-specific antibody and IFN- $\gamma$ produced by T cells and possibly neurons. This effectively inhibits the production of new virus, but does not necessarily eliminate virus RNA from the cell. $\mathrm{CD}^{+} \mathrm{T}$ cells that secrete cytokines, such as IFN- $\gamma$, and antibody-secreting B cells are resident for prolonged periods of time in the nervous system and probably have a role in long-term control of virus replication. $\mathbf{b}$ | Initial control of virus replication in infected glial cells involves IFN- $\beta$. Clearance involves cytolytic CD8 ${ }^{+} T$ cells. CD4 ${ }^{+} T$ cells supply help for $C D 8^{+} T$ cells and both subsets of $T$ cells produce IFN- $\gamma$, which has an independent role in virus clearance from cells that survive. Long-term control of virus replication requires the local production of virus-specific antibody and possibly $T$ cells.

It is interesting that some neurons can produce IFN- $\gamma^{19}$, and the autocrine effects of IFN- $\gamma$ might also have a role in virus clearance ${ }^{100}$. In all of these examples of virus clearance, no infectious virus can be recovered, but virus RNA in the CNS remains detectable by sensitive techniques - such as PCR after reverse transcription of RNA (RT-PCR) - and this RNA is presumed to reside in infected neurons that survived both infection and immune-mediated virus clearance $e^{77,82}$.

Clearance from glial cells. Clearance of infectious virus from glial cells seems to be more complicated than clearance from neurons and is probably dependent on $\mathrm{T}$ cells (FIG. 2), perhaps because these cells are more likely to be induced by inflammatory mediators to express MHC molecules. In the best-studied examples of virus infection of glial cells - TMEV and MHV - clearance mechanisms often fail, which results in persistent infection and immune-mediated demyelinating disease in susceptible strains of mice. TMEV has an early encephalitic phase, which mainly involves infection of neurons, followed, in genetically susceptible strains of mice, by persistent infection of glial cells. Clearance of TMEV from strains of mice that do not develop persistent infection or demyelinating disease is dependent on a rapid $\mathrm{CD} 8^{+} \mathrm{T}$-cell response ${ }^{101}$. In strains of mice that are susceptible to persistent infection, infectious virus is cleared from neurons, but virus is not completely cleared from oligodendrocytes, astrocytes and microglia, although it is reduced to low levels, and infectious virus can be cultured from the CNS.

The JHM strain of MHV (MHV4) mainly infects glial cells. Although passive antibody can protect mice from fatal encephalomyelitis, in strains of mice that clear the infection, antibody is not detectable until after the virus is cleared, which indicates that antibody is not the main mechanism of clearance ${ }^{28,102,103}$. A reduction in virus replication can be mediated by $\mathrm{CD}^{+}$or $\mathrm{CD}^{+}$ $\mathrm{T}_{\text {cells }}{ }^{104,105}$, and transfer of virus-specific $\mathrm{CD} 4^{+}$or $\mathrm{CD}^{+}$ $\mathrm{T}$ cells can protect from fatal MHV-induced encephalitis $^{104}$, which further indicates a role for T cells in control of virus replication.

The mechanism of T-cell-mediated clearance of MHV is glial-cell-type specific ${ }^{102}$. IFN- $\gamma$ is particularly important for the clearance of MHV from oligodendrocytes, whereas perforin, and presumably $\mathrm{CD} 8^{+}$ 
T-cell-mediated cytolysis, is important for the clearance of virus from astrocytes and microglia ${ }^{103,105,106}$. Clearance occurs in perforin-deficient mice but is delayed, indicating that many mechanisms are involved ${ }^{103}$. Auxiliary roles have been identified for $\mathrm{CD} 4^{+} \mathrm{T}$ cells, $\mathrm{CD} 95$ and IFN- $\gamma$ in virus clearance ${ }^{98,107}$. CD4 ${ }^{+} \mathrm{T}$-cell help is required for the prevention of apoptosis and expression of the cytotoxic effector function of $\mathrm{CD} 8^{+} \mathrm{T}$ cells in the MHV-infected $\mathrm{CNS}^{56}$. Virus RNA that persists can resume replication and, therefore, long-term local immune control of virus replication is required ${ }^{60}$. IFN- $\gamma$-secreting $C D 8^{+} \mathrm{T}$ cells that are specific for virus antigen persist in the CNS and might contribute to the demyelinating process that follows resolution of the acute virus infection ${ }^{108-110} . \mathrm{CD}^{+} \mathrm{T}$ cells also persist in the CNS for several weeks ${ }^{60}$. Despite a lack of evidence for a role for antibody in the initial clearance of MHV, antibody-secreting B cells are essential for the prevention of renewed virus replication ${ }^{111}$. T-cell numbers eventually decline, but antibody-secreting $B$ cells persist ${ }^{57}$. Both $B$ cells and the virus-specific antibody they produce seem to have independent roles in preventing the renewed replication of MHV in astrocytes and oligodendrocytes ${ }^{11,112}$. Although $B$ cells can be cytotoxic in vitro, it is not clear whether this mechanism is relevant to the role of B cells in vivo.

\section{Concluding remarks}

Although there is an increasing understanding of many of the unique aspects of the immune responses to virus infections of the CNS, many questions remain unanswered. The adhesion molecules expressed by endothelial cells and lymphocytes that are responsible for entry of the earliest $\mathrm{T}$ and $\mathrm{B}$ cells involved in immune surveillance and initiation of inflammation are unclear. The molecular mechanisms involved in non-cytolytic virus clearance from neurons are not defined for any of the model infections that are being studied. Knowledge of these mechanisms would allow the identification of cell-type-dependent differences - that is, between different neuronal populations, oligodendroglia, astrocytes and microglia — in response to various immune mediators, such as IFNs and antibodies. Another important area of investigation will be the use of new genetic information to identify host determinants that affect inflammation, virus persistence in the CNS, and host susceptibility to fatal virus and immune-mediated disease. This information will help the development of new treatments for infections of the CNS caused by RNA viruses. For example, knowing the target virus proteins and contributions of specific components of the immune response will help in rational vaccine design. In addition, the ability of passively transferred immune serum that contains polyclonal antibody to aid the clearance of virus indicates that therapeutic monoclonal antibodies can be developed for post-exposure prophylaxis. This could potentially be combined with the appropriate use of cytokines that are involved in virus clearance. Whether such approaches would be therapeutically useful after the development of symptoms that are associated with neuronal loss or dysfunction is less clear.
1. Ehrengruber, M. U., Ehler, E., Billeter, M. A. \& Naim, H. Y. Measles virus spreads in rat hippocampal neurons by cell-to-cell contact and in a polarized fashion. J. Virol. 76 5720-5728 (2002).

2. Stevenson, P. G., Freeman, S., Bangham, C. R. \& Hawke, S. Virus dissemination through the brain parenchyma without immunologic control. J. Immunol. 159, 1876-1884 (1997).

3. Hoek, R. M. et al. Down-regulation of the macrophage lineage through interaction with OX2 (CD200). Science 290 lineage through inter

CD200-CD200R-mediated interactions between neurons and microglia are essential for maintenance of the anti-inflammatory state in the central nervous system (CNS).

4. Neumann, H., Misgeld, T., Matsumuro, K. \& Wekerle, H. Neurotrophins inhibit major histocompatibility class inducibility of microglia: involvement of the 75 neurotroph inducibity of

5. Johnson, M. D. Gold, L. I. \& Moses, H. L. Evidence for transforming growth factor- $\beta$ expression in human transforming growth factor- $\beta$ expression in human
leptomeningeal cells and transforming growth factor- $\beta$-like leptomeningeal cells and transforming growth factor- $\beta$
activity in human cerebrospinal fluid. Lab. Invest. 67 , 360-368 (1992).

6. Fabry, Z. et al. TGF- $\beta 2$ decreases migration of lymphocytes in vitro and homing of cells into the central nervous system in vivo. J. Immunol. 155, 325-332 (1995).

7. Muller, $U$. et al. Functional role of type I and type II interferons in antiviral defense. Science 264, 1918-1921 (1994). This paper reports the development of mice that are This paper reports the development of mice that are
deficient in receptors for interferon- $\alpha / \beta$ (IFN- $\alpha / \beta)$ and deficient in receptors for interferon- $\alpha / \beta$ (IFN- $\alpha / \beta)$
IFN- $\gamma$ and indicates the essential role of these receptors in the control of virus replication.

8. Fiette, L. et al. Theilers virus infection of $129 \mathrm{SV}$ mice that lack the interferon- $\alpha / \beta$ or interferon- $\gamma$ receptors. J. Exp. Med. 181, 2069-2076 (1995).

9. Ryman, K., Klimstra, W., Nguyen, K., Biron, C. \& Johnston, R. $\alpha / \beta$ interferon protects adult mice from fatal Sindbis virus infection and is an important determinant of cell and tissue tropism. J. Virol. 74, 3366-3378 (2000).
10. Byrnes, A. P., Durbin, J. E. \& Griffin, D. E. Control of Sindbis virus infection by antibody in interferon-deficient mice. J. Virol. 74, 3905-3908 (2000).

11. Sandberg, K., Eloranta, M. L. \& Campbell, I. L. Expression of $\alpha / \beta$ interferons (IFN- $\alpha / \beta)$ and their relationship to IFN- $\alpha / \beta$-induced genes in lymphocytic choriomeningitis. J. Virol. 68, 7358-7366 (1994).

12. Erlandsson, L. et al. Interferon $-\beta$ is required for interferon- $\alpha$ production in mouse fibroblasts. Curr. Biol. 8, 223-226 (1998)

13. Akwa, Y. et al. Transgenic expression of IFN- $\alpha$ in the central nervous system of mice protects against lethal neurotropic viral infection but induces inflammation and neurodegeneration. J. Immunol. 161, 5016-5026 (1998).

14. McLaurin, J., Antel, J. P. \& Yong, V. W. Immune and nonimmune actions of interferon- $\beta-1 \mathrm{~b}$ on primary human neural cells. Multiple Sclerosis 1, 10-19 (1995).

15. Boutros, T., Croze, E. \& Yong, V. W. Interferon- $\beta$ is a potent promoter of nerve growth factor production by astrocytes. J. Neurochem. 69, 939-946 (1997).

16. Chabot, S. \& Yong, V. W. Interferon- $\beta$ - 1 b increases interleukin-10 in a model of $\mathrm{T}$ cell-microglia interaction: relevance to MS. Neurology 55, 1497-1505 (2000).

17. van Pesch, V., van Eyll, O. \& Michiels, T. The leader protein of Theiler's virus inhibits immediate-early $\alpha / \beta$ interferon production. J. Virol. 75, 7811-7817 (2001).

18. Neumann, $\mathrm{H}$. Control of glial immune function by neurons. Glia 36, 191-199 (2001).

19. Neumann, H. Schmidt, H., Wilharm, E., Behrens, L. \& Wekerle, H. Interferon $\gamma$ gene expression in sensory neurons: evidence for autocrine gene regulation. J. Exp. Med. 186, 2023-2031 (1997). This paper describes for the first time that neurons produce IFN- $\gamma$.

20. Harrison, J. K. et al. Role for neuronally derived fractalkine in mediating interactions between neurons and CX3CR1 expressing microglia. Proc. Nat/ Acad. Sci. USA 95 10896-10901 (1998).
21. Rappert, A. et al. Secondary lymphoid tissue chemokine (CCL21) activates CXCR3 to trigger a CI(-) current and chemotaxis in murine microglia. J. Immunol. 168 3221-3226 (2002).

22. Chapman, G. A. et al. Fractalkine cleavage from neurona membranes represents an acute event in the inflammatory response to excitotoxic brain damage. J. Neurosci. 20, 1-5 (2000).

The authors describe that neurons use the chemokine The authors describe that neurons use the chemokine
fractalkine (CX3CL1) to signal the presence of injury to microglia.

23. Jung, S. et al. Analysis of fractalkine receptor CX3CR1 function by targeted deletion and green fluorescent protein reporter gene insertion. Mol. Cell Biol. 20, 4106-4114 (2000).

24. Maciejewski-Lenoir, D., Chen, S., Feng, L., Maki, R. \& Bacon, K. B. Characterization of fractalkine in rat brain cells: migratory and activation signals for CX3CR-1-expressing microglia. J. Immunol. 163, 1628-1635 (1999).

25. Asensio, V. C. \& Campbell, I. L. Chemokine gene expression in the brains of mice with lymphocytic choriomeningitis. J. Virol. 71, 7832-7840 (1997).

26. Lane, T. E. et al. Dynamic regulation of $\alpha$ - and $\beta$-chemokine expression in the central nervous system during mouse hepatitis virus-induced demyelinating disease. J. Immunol. 160, 970-978 (1998).

27. Wesselingh, S. L., Levine, B., Fox, R. J., Choi, S. \& Griffin, D. E. Intracerebral cytokine mRNA expression during fatal and nonfatal alphavirus encephalitis suggests a predominant type 2 T cell response. J. Immunol. 152, 1289-1297 (1994).

28. Parra, B., Hinton, D. R., Lin, M. T., Cua, D. J. \& Stohlman, S. A. Kinetics of cytokine mRNA expression in the central nervous system following lethal and nonlethal coronavirusinduced acute encephalomyelitis. Virology 233, 260-270 (1997).

29. Chang, J. R., Zaczynska, E., Katsetos, C. D., Platsoucas, C. D. \& Oleszak, E. L. Differential expression of TGF- $\beta$, IL-2, and other cytokines in the CNS of Theiler's murine encephalomyelitis virus-infected susceptible and resistant strains of mice. Virology 278, 346-360 (2000). 
30. Galelli, A., Baloul, L. \& Lafon, M. Abortive rabies virus central nervous infection is controlled by T lymphocyte loca recruitment and induction of apoptosis. J. Neurovirol. 6, 359-372 (2000).

31. Middleton, J., Patterson, A. M., Gardner, L., Schmutz, C. \& Ashton, B. A. Leukocyte extravasation: chemokine transport and presentation by the endothelium. Blood 100 3853-3860 (2002).

32. Harling-Berg, C. J., Park, T. J. \& Knopf, P. M. Role of the cervical lymphatics in the $\mathrm{T}_{2} 2$-type hierarchy of CNS immune regulation. J. Neuroimmunol. 101, 111-127 (1999).

33. Fischer, H. G. \& Reichmann, G. Brain dendritic cells and macrophages/microglia in central nervous system inflammation. J. Immunol. 166, 2717-2726 (2001).

34. Pope, J. G., Vanderlugt, C. L., Rahbe, S. M., Lipton, H. L. \& Miller, S. D. Characterization of and functional antigen presentation by central nervous system mononuclear cells from mice infected with Theiler's murine encephalomyelitis virus. J. Virol. 72, 7762-7771 (1998).

35. McMenamin, P. G. Distribution and phenotype of dendritic cells and resident tissue macrophages in the dura mater, leptomeninges, and choroid plexus of the rat brain as demonstrated in wholemount preparations. J. Comp. Neurol. 405, 553-562 (1999).

36. Cserr, H. F. \& Knopf, P. M. Cenvical lymphatics, the blood-brain barrier and the immunoreactivity of the brain: a new view. Immunol. Today 13, 507-512 (1992).

37. Stevenson, P. G., Hawke, S., Sloan, D. J. \& Bangham, C. R. The immunogenicity of intracerebral virus infection depends on anatomical site. J. Virol. 71, 145-151 (1997).

38. Carrithers, M. D., Visintin, I., Kang, S. J. \& Janeway, C. A. Jr. Differential adhesion molecule requirements for immune surveillance and inflammatory recruitment. Brain 123 1092-1101 (2000).

39. Irani, D. N. \& Griffin, D. E. Regulation of lymphocyte homing into the brain during viral encephalitis at various states of infection. J. Immunol. 156, 3850-3857 (1996).

40. Wekerle, H., Linington, C., Lassman, H. \& Meyermann, R. Cellular immune reactivity within the CNS. Trends Neurosci. 9, 271-277 (1986). The authors show that activated $T$ cells can enter the normal CNS.

41. Hickey, W. F., Hsu, B. L. \& Kimura, H. T-lymphocyte entry into the central nervous system. J. Neurosci. Res. $\mathbf{2 8}$, 254-260 (1991).

42. Piccio, L. et al. Molecular mechanisms involved in lymphocyte recruitment in inflamed brain microvessels: critical roles for $\mathrm{P}$-selectin glycoprotein ligand-1 and critical roles for P-selectin glycoprotein ligand-1 and 1940-1949 (2002).

43. Hickey, W. F. Basic principles of immunological surveillance of the normal central nervous system. Glia $\mathbf{3 6}, 118-124$ (2001)

44. Licinio, J. \& Wong, M. L. Pathways and mechanisms for cytokine signaling of the central nervous system. J. Clin. Invest. 100, 2941-2947 (1997).

45. Alt, C., Laschinger, M. \& Engelhardt, B. Functional expression of the lymphoid chemokines CCL19 (ELC) and CCL21 (SLC) at the blood-brain barrier suggests their involvement in G-protein-dependent lymphocyte recruitment into the central nervous system during experimental autoimmune encephalomyelitis. Eur. J. Immunol. 32, 2133-2144 (2002).

46. Kimura, T. \& Griffin, D. E. The role of $\mathrm{CD} 8^{+} \mathrm{T}$ cells and major histocompatibility complex class I expression in the central nervous system of mice infected with neurovirulent Sindbis virus. J. Virol. 74, 6117-6125 (2000).

47. Suzumura, A. et al. Induction of glial cell $\mathrm{MHC}$ antigen expression in neurotropic coronavirus infections. Characterization of the $\mathrm{H}$-2-inducing soluble facto elaborated by infected brain cells. J. Immunol. 140 2068-2072 (1988).

48. Massa, P. T., Whitney, L. W., Wu, C., Ropka, S. L. \& Jarosinski, K. W. A mechanism for selective induction of $2^{\prime}-5$ ' oligoadenylate synthetase, anti-viral state, but not $\mathrm{MHC}$ class I genes by interferon- $\beta$ in neurons. J. Neurovirol. 5, 161-171 (1999).

49. Jarosinski, K. W. Whitney, L. W. \& Massa, P. T. Specific deficiency in nuclear factor- $\mathrm{KB}$ activation in neurons of the central nervous system. Lab. Invest. 81, 1275-1288 (2001).

50. Neumann, H., Schmidt, H., Cavalie, A., Jenne, D. 8 Wekerle, H. Major histocompatibility complex (MHC) class gene expression in single neurons of the central nervous system: differential regulation by interferon (IFN)- $\gamma$ and tumor
necrosis factor (TNF)- . J. Exp. Med. 185, 305-316 (1997).

51. Pereira, R. A. \& Simmons, A. Cell surface expression of H2 antigens on primary sensory neurons in response to acute but not latent herpes simplex virus infection in vivo. J. Virol. 73, 6484-6489 (1999).
52. Sedgwick, J. D., Ford, A. L., Foulcher, E. \& Airriess, R Central nervous system microglial cell activation and proliferation follows direct interaction with tissue-infiltrating T cell blasts. J. Immunol. 160, 5320-5330 (1998).

53. Irani, D. N. \& Griffin, D. E. Isolation of brain parenchymal lymphocytes for flow cytometric analysis. Application to acute viral encephalitis. J. Immunol. Methods 139, 223-231 (1991).

54. Hatalski, C. G., Hickey, W. F. \& Lipkin, W. I. Evolution of the immune response in the central nervous system following infection with Borna disease virus. J. Neuroimmunol $\mathbf{9 0}$ 137-142 (1998).

55. Haring, J. S., Pewe, L. L. \& Perlman, S. High-magnitude, virus-specific CD4 T-cell response in the central nervous system of coronavirus-infected mice. J. Virol. $\mathbf{7 5}$, 3043-3047 (2001)

56. Stohlman, S. A., Bergmann, C. C., Lin, M. T., Cua, D. J. \& Hinton, D. R. CTL effector function within the central nervous system requires $\mathrm{CD} 4^{+} \mathrm{T}$ cells. J. Immunol. $\mathbf{1 6 0}$ 2896-2904 (1998).

57. Tschen, S. I. et al. Recruitment kinetics and composition of antibody-secreting cells within the central nervous system following viral encephalomyelitis. J. Immunol. 168 2922-2929 (2002)

58. Dorries, R. The role of T-cell-mediated mechanisms in virus infections of the nervous system. Curr. Top. Microbiol. Immunol. 253, 219-245 (2001).

59. Pashenkov, M. \& Link, H. Dendritic cells and immune responses in the central nervous system. Trends Immunol. 23, 69-70 (2002).

60. Marten, N. W., Stohlman, S. A. \& Bergmann, C. C. Role of viral persistence in retaining $\mathrm{CD} 8^{+} \mathrm{T}$ cells within the centra nervous system. J. Virol. 74, 7903-7910 (2000).

61. Pearce, B. D., Hobbs, M. V., McGraw, T. S. \& Buchmeier, M. J. Cytokine induction during T-cell-mediated clearance of mouse hepatitis virus from neurons in vivo. J. Virol. 68 , 5483-5495 (1994).

62. Rowell, J. F. \& Griffin, D. E. The inflammatory response to nonfatal Sindbis virus infection of the nervous system is more severe in SJL than in BALB/c mice and is associated with low levels of IL-4 mRNA and high levels of IL-10producing CD4+ T cells. J. Immunol. 162, 1624-1632 (1999).

63. Griffin, D. E. Immunoglobulins in the cerebrospinal fluid: changes during acute viral encephalitis in mice. J. Immunol. 126, 27-31 (1981).

64. Irani, D. N., Lin, K.-I. \& Griffin, D. E. Brain-derived gangliosides regulate the cytokine production and proliferation of activated T cells. J. Immunol. 157, proliferation of activ

65. Irani, D. N., Lin, K.-I. \& Griffin, D. E. Regulation of brainderived $T$ cells during acute central nervous system inflammation. J. Immunol. 158, 2318-2326 (1997).

66. Massa, P. T. Specific suppression of major histocompatibility complex class I and class II genes in astrocytes by brainenriched gangliosides. J. Exp. Med. 178, 1357-1363 (1993).

67. Irani, D. N. The susceptibility of mice to immune-mediated neurologic disease correlates with the degree to which their lymphocytes resist the effects of brain-derived gangliosides. J. Immunol. 161, 2746-2752 (1998). This paper shows that brain gangliosides regulat T-cell responses in the CNS.

68. Tontsch, U. \& Rott, O. Cortical neurons selectively inhibit $\mathrm{MHC}$ class II induction in astrocytes but not in microglia cells. Int. Immunol. 5, 249-254 (1993).

69. Ford, A. L., Foulcher, E., Lemckert, F. A. \& Sedgwick, J. D. Microglia induce CD4 T lymphocyte final effector function and death. J. Exp. Med. 184, 1737-1745 (1996).

70. Gordon, L. B., Nolan, S. C., Ksander, B. R., Knopf, P. M. \& Harling-Berg, C. J. Normal cerebrospinal fluid suppresses the in vitro development of cytotoxic $\mathrm{T}$ cells: role of the brain microenvironment in CNS immune regulation. J. Neuroimmunol. 88, 77-84 (1998).

71. Hailer, N. P., Heppner, F. L., Haas, D. \& Nitsch, R. Astrocytic factors deactivate antigen presenting cells that invade the central nervous system. Brain Pathol 8, 459-474 (1998).

72. Bauer, J. et al. T-cell apoptosis in inflammatory brain lesions: destruction of $T$ cells does not depend on antigen recognition. Am. J. Pathol. 153, 715-724 (1998).

73. Gold, R. et al. Antigen presentation by astrocytes primes rat T lymphocytes for apoptotic cell death. A model for T-cell apoptosis in vivo. Brain 119, 651-659 (1996).

74. Medana, I. et al. Fas ligand (CD95L) protects neurons against perforin-mediated T lymphocyte cytotoxicity. J. Immunol. 167, 674-681 (2001).

75. Flugel, A. et al. Neuronal FasL induces cell death of encephalitogenic T lymphocytes. Brain Pathol. 10, 353-364 (2000).
76. Shin, D. H. et al. Fas ligand mRNA expression in the mouse central nervous system. J. Neuroimmunol. 123, 50-57 (2002).

77. Hawke, S., Stevenson, P. G., Freeman, S. \& Bangham, C. R. Long-term persistence of activated cytotoxic T lymphocytes after viral infection of the central nervous system. J. Exp. Med. 187, 1575-1582 (1998).

78. Fujinami, R. S., Rosenthal, A., Lampert, P. W., Zurbriggen, A. \& Yamada, M. Survival of athymic (nu/nu) mice after Theiler's murine encephalomyelitis virus infection by passive administration of neutralizing monoclonal antibody. J. Virol. 63, 2081-2087 (1989).

79. Fleming, J. O., Shubin, R. A., Sussman, M. A., Casteel, N. \& Stohlman, S. A. Monoclonal antibodies to the matrix ( $E 1$ ) glycoprotein of mouse hepatitis virus protect mice from encephalitis. Virology 168, 162-167 (1989).

80. Levine, B. et al. Antibody-mediated clearance of alphavirus infection from neurons. Science 254, 856-860 (1991). This was the first paper to show that antibody can mediate non-cytolytic clearance of virus from neurons.

81. Perry, L. L. \& Lodmell, D. L. Role of CD $4^{+}$and $C D 8^{+}$T cells in murine resistance to street rabies virus. J. Virol. $\mathbf{6 5}$, 3429-3434 (1991).

82. Tyor, W. R., Wesselingh, S., Levine, B. \& Griffin, D. E. Long term intraparenchymal Ig secretion after acute viral encephalitis in mice. J. Immunol. 149, 4016-4020 (1992).

83. Hatalski, C. G., Hickey, W. F. \& Lipkin, W. I. Humoral immunity in the central nervous system of Lewis rats infected with Borna disease virus. J. Neuroimmunol. 90 128-136 (1998).

84. Ubol, S., Levine, B., Lee, S.-H., Greenspan, N. S. \& Griffin, D. E. Roles of immunoglobulin valency and the heavy-chain constant domain in antibody-mediated downregulation of Sindbis virus replication in persistently infected neurons. J. Virol. 69, 1990-1993 (1995).

85. Despres, P., Griffin, J. W. \& Griffin, D. E. Effects of anti-E2 monoclonal antibody on Sindbis virus replication in AT3 cells expressing Bcl-2. J. Virol. 69, 7006-7014 (1995)

86. Despres, P., Griffin, J. W. \& Griffin, D. E. Antiviral activity of $\alpha$-interferon in Sindbis virus-infected cells is restored by antiE2 monoclonal antibody treatment. J. Virol. 69, 7345-7348 (1995).

87. Hooper, D. C. et al. Collaboration of antibody and inflammation in clearance of rabies virus from the central nervous system. J. Virol. 72, 3711-3719 (1998).

88. Destombes, J. et al. Persistent poliovirus infection in mouse motoneurons. J. Virol. 71, 1621-1628 (1997)

89. Liu, T., Khanna, K. M., Carriere, B. N. \& Hendricks, R. L. $\gamma$-interferon can prevent herpes simplex virus type 1 reactivation from latency in sensory neurons. J. Virol. 75, 11178-11184 (2001).

90. Neumann, H., Cavalie, A., Jenne, D. E. \& Wekerle, H. Induction of MHC class 1 genes in neurons. Science $\mathbf{2 6 9}$ 549-552 (1995).

\section{This paper describes that damaged neurons can} express MHC class I molecules in response to IFN- $\gamma$.

91. Medana, I. M. et al. MHC class I-restricted killing of neurons by virus-specific $\mathrm{CD} 8^{+} \mathrm{T}$ lymphocytes is effected through the Fas-FasL, but not the perforin pathway. Eur. J. Immunol. 30, 3623-3633 (2000).

92. Bilzer, T. \& Stitz, L. Immune-mediated brain atrophy. CD8 ${ }^{+}$ $T$ cells contribute to tissue destruction during borna disease. J. Immunol. 153, 818-823 (1994).

\section{This study provides evidence that populations of} neurons differ in their susceptibility to IFN- $\gamma$-mediated virus clearance.

93. Patterson, C. E., Lawrence, D. M., Echols, L. A. \& Rall, G. F. Immune-mediated protection from measles virus-induced central nervous system disease is noncytolytic and $\gamma$-interferon dependent. J. Virol 76, 4497-4506 (2002).

94. Binder, G. \& Griffin, D. Interferon- $\gamma$-mediated site specific clearance of alphavirus from CNS neurons. Science $\mathbf{2 9 3}$ 303-306 (2001).

95. Komatsu, T., Ireland, D. D., Chen, N. \& Reiss, C. S. Neuronal expression of NOS-1 is required for host recovery from viral encephalitis. Virology 258, 389-395 (1999).

96. Oldstone, M. B., Blount, P., Southern, P. J. \& Lampert, P. W. Cytoimmunotherapy for persistent virus infection reveals a unique clearance pattern from the central nervous system. Nature 321, 239-243 (1986).

97. Pereira, R. A., Simon, M. M. \& Simmons, A. Granzyme A, a noncytolytic component of $\mathrm{CD} 8^{+}$cell granules, restricts the spread of herpes simplex virus in the peripheral nervous systems of experimentally infected mice. J. Virol. $\mathbf{7 4}$ 1029-1032 (2000).

98. Lin, M. T., Hinton, D. R. \& Stohlman, S. A. Mechanisms of viral clearance in perforin-deficient mice. Adv. Exp. Med. Biol. 440, 431-436 (1998). 
99. Robertson, B., Kong, G., Peng, Z., Bentivoglio, M. \& Kristensson, K. Interferon- $\gamma$-responsive neuronal sites in the normal rat brain: receptor protein distribution and cell activation revealed by Fos induction. Brain Res. Bull. 52 , 61-74 (2000).

100. Eneroth, A. et al. Interferon- $\gamma$-like immunoreactivity in sensory neurons may influence the replication of Sendai and mumps viruses. J. Neurosci. Res. 31, 487-493 (1992).

101. Lindsley, M. D. \& Rodriguez, M. Characterization of the inflammatory response in the central nervous system of inflammatory response in the central nervous system of mice susceptible or resistant to demyelination
virus. J. Immunol. 142, 2677-2682 (1989).

102. Korner, H. et al. Nucleocapsid or spike protein-specific $\mathrm{CD}^{+}$T lymphocytes protect against coronavirus-induced encephalomyelitis in the absence of CD8 ${ }^{+} \mathrm{T}$ cells. J. Immunol. 147, 2317-2323 (1991).

103. Lin, M. T., Stohlman, S. A. \& Hinton, D. R. Mouse hepatitis virus is cleared from the central nervous systems of mice lacking perforin-mediated cytolysis. J. Virol. 71, 383-391 (1997).

104. Yamaguchi, K., Goto, N., Kyuwa, S., Hayami, M. \& Toyoda, Y. Protection of mice from a lethal coronavirus infection in the central nervous system by adoptive transfer of virus-specific T cell clones. J. Neuroimmunol. 32, 1-9 (1991).

105. Stohlman, S. A., Bergmann, C. C., Van der Veen, R. C. \& Hinton, D. R. Mouse hepatits virus-specific cytotoxic T lymphocytes protect from lethal infection without eliminating virus from the central nervous system. J. Virol. 69, 684-694 (1995).

106. Parra, B. et al. IFN- $\gamma$ is required for viral clearance from central nervous system oligodendroglia. J. Immunol. 162 1641-1647 (1999)

107. Parra, B. et al. Contributions of Fas-Fas ligand interactions to the pathogenesis of mouse hepatitis virus in the central nervous system. J. Virol. 74, 2447-2450 (2000)

108. Marten, N. W. et al. Contributions of $C D 8^{+} T$ cells and viral spread to demyelinating disease. J. Immunol. 164, 4080-4088 (2000)

109. Marten, N. W. et al. Selection of CD8 ${ }^{+}$T cells with highly focused specificity during viral persistence in the centra nervous system. J. Immunol. 162, 3905-3914 (1999).

110. Bergmann, C. C., Altman, J. D., Hinton, D. \& Stohlman, S. A. Inverted immunodominance and impaired cytolytic function of $\mathrm{CD}^{+} \mathrm{T}$ cells during viral persistence in the central nervous system. J. Immunol. 163, 3379-3387 (1999).

111. Ramakrishna, C., Stohlman, S. A., Atkinson, R. D. Shlomchik, M. J. \& Bergmann, C. C. Mechanisms of central Shlomchk, M. J. \& Bergm, C. C. Mech, R. D., ef centra nervous system viral persistence: the citical role of an and B cells. J. Immunol. 168, 1204-1211 (2002).

$A$ report showing that $B$ cells are required to preven renewed replication of coronavirus in glial cells afte initial T-cell-mediated control of replication.
112. Morales, S., Parra, B. Ramakrishna, C., Blau, D. M. \& Stohlman, S. A. B-cell-mediated lysis of cells infected with the neurotropic JHM strain of mouse hepatitis virus. Virology 286, 160-167 (2001).

Acknowledgements

Work in my laboratory was supported by a research grant from the National Institutes of Health.

\section{(D) Online links}

\section{DATABASES}

The following terms in this article are linked online to: LocusLink: http://www.ncbi.nlm.nih.gov/LocusLink/ CCL2 | CCL4 | CCL5 | CCL7 | CCL21 | CD95 | CD95L | CD200 | CX3CL1 | CXCL10 | ICAM1 | IFN- $\alpha$ | IFN- $\beta$ | IFN- $\gamma \mid$ |L-1 | IL-6 | LL-12 | LFA1 | perforin | TGF- $\beta$ | TNF | VCAM1 OMIM: http///www ncbinlmnih

Borna disease virus | herpes simplex virus | lymphocytic choriomeningitis virus | mouse hepatitis virus | rabies virus | Semliki Forest virus | Sindbis virus | Theiler's mouse encephalomyelitis virus | Venezuelan equine encephalitis virus | vesicular stomatitis virus

Access to this interactive links box is free online. 